\title{
ORGANIZATIONAL STRUCTURE DESIGN OF CONTROLLING INVESTMENT AND INNOVATION PROCESSES IN THE SUBJECTS OF SMALL ENTREPRENEURSHIP
}

\author{
Yury Anatolievich Doroshenko \\ Belgorod State Technological University named after V.G. Shukhov \\ Irina Vladimirovna Somina \\ Belgorod State Technological University named after V.G. Shukhov \\ Irina Vladimirovna Yarmolenko \\ Belgorod State Technological University named after V.G. Shukhov \\ Ilia Viktorovich Afanasiev \\ Belgorod State Technological University named after V.G. Shukhov \\ Vladimir Leonidovich Kurbatov \\ North Caucasian branch of the Belgorod State Technological University
}

The paper investigated the possibilities of using the traditional organizational structures of economic entities for solving the functional issues of investment and innovation. It was revealed that the greatest challenges of innovation and investment processes in small enterprises, corresponds matrix structure that allows use of the potential owners, managers and employees of small enterprises, which can act in one person, within not one but several innovative and investment projects. It is proved that the formation of matrix organizational structures in small enterprises should be carried out in the direction of selection and subordination linear functional elements and design of organizational structures, establishment of a mechanism of dual subordination on the basis of bilateral ties and orientation to minimize risks and ensure the best innovative features of the investees. To modify the basic linear structures investment management innovation in the subjects of small business prompted the creation of micro focus groups among owner-managers of small companies and key line departments.

Key words: Organizational structure, Investment and innovation processes, Subjects of small entrepreneurship, Micro focus group

\section{INTRODUCTION}

Nowadays special role in the modern economy, innovative economy belongs to small businesses. Small businesses with a highly qualified staff, market and technological flexibility, the ability to take risks, often achieved much greater success in the design and development of radically new products and technologies than large businesses. International experience showsthat technological solutions that can make a revolution in an industry born usually exactlyin sphere of small innovative businesses.In this regard, well-known researcher of the material culture of the market and entrepreneurship F. Braudel, studying English industrial revolution, noted that historically machinery stagnates or moves from one "revolution" to another one, from one innovation to the next one and the technique does not exist by itself, but society dictates its will in the implementation of technological progress, which detain thousands of reasons, including the possibility of labor remain without application or unwillingness of entrepreneurs to innovate for reasons of cost [01]. As a result we can conclude that in the present economic conditions the functioning of the world economy such restrictions are retained for large and medium enterprises, but on the contrary, they overcome by small businesses, because small businesses, in most cases, the functions as the owner, the manager 
and the employee are the same, from one hand, there is no need to reduce the number of employees of small businesses, on the other hand, creates an additional motivation for the introduction of innovative technical means and appropriate investment.Based on the previously formed the methodological aspects of investment and innovation processes in small business $[02,03]$ and a basic views of organizational relations in management [04, 05 and etc.], research issues of organizational planning in the subjects of small business in the context of investment and innovation of its activities.

\section{THE METHODOLOGY}

There is a generally accepted approach in modern economic literature according to which the organization - a group of people whose activities are consciously coordinated to achieve a common goal or goals [05]. Such characteristic of the organization is in the foreign sources and domestic experts approved it. Russian researchers emphasize that the organization is not just a group of people, but the device, a way of association, relations, interaction of participants, respectively, in terms of structural approach, the organization allocated industrial structure, technological structure, ownership structure and organizational management structure, and the latest one is the main instrument of detail regulation and fixing the composition and content of the various resources of the organization [06]. As a rule in the description of the organization noted that it contains a horizontal division of labor, in the form of separation of all work on making components, including through the education departments and vertical division of labor when work on coordination is separated from the actions themselves. In terms of the investment process, the organization's objectives in general and its individual divisions may varydue to the nature of the internal environment of the organization. At the same time in the organizations belonging to small business this difference is minimal.

\section{POSSIBILITY OF USING THE TRADITIONAL ORGANIZATIONAL STRUCTURES FOR MANAGEMENT \& INVESTMENT INNOVATION PROCESS}

We investigate the types of organizational structures whichin the best way adapted to the investment and innovation. Usually they are based on linear relationships involving the transfer of au- thority directly from the head to the slave, and staff relations, including the powers of recommendation, approval, parallel and functional powers are realized through the apparatus. In economic practice line and staff authority are interact. Typically, organizational design for companies of any size organization involves dividing the horizontal blocks, setting the ratio of the various positions and powers to be identified as a set of specific tasks and functions [07].

There are a lot sufficient details and precisely describes the various forms of organizational structures in the modern economic literature. So, it decided to allocate, on the one side, the hierarchical organizational structures (formal, mechanistic, bureaucratic, classic, traditional), characterized by a rigid hierarchy of power in the company formalized rules and procedures, centralized decision-making, formal relations staff, on the other side, adaptive organization structure (organic, flexible), which are peculiar to blur management hierarchy, a small number of layers of management, flexibility, moderate use of formal rules and procedures, decentralization of decision-making, informal relations staff. Thus a hierarchical organizational structures are usually related to a linear function, linear-staff, a linearly-functional and divisional organizational structure, to adaptive - project, and matrix problem-group structure [08].

Thelinear management structure is the most common in the Russian and international practice wherein the vertical hierarchy and the direct influence of the leaders to the employees. Here there is unity of stewardship, the high degree of division of labor and efficiency in decision-making, the presence of a chain of commands, numerous rules and standards for staff recruitment on the business and professional skills, thus prevail in the first place, line authority. Linear organizational structure can be used for manage the investment and innovation processes in large and medium-sized enterprises, especially in cases when it is modified in a linearly-staff management structure with the creation of line managers in the staff services, specializing in the implementation of investment and innovation functions. However, it is not suitable for investment and innovation activities of small businesses due to the fact that they do not have the levels of branched-chain management, in fact, the participants in the investment management process innovation directly and closely interact at the same time as owners, senior managers and 
employees of small businesses. In addition to the linear organizational structure is quite typical for enterprise management is a functional organizational structure. In this case, each unit in the organization specializes in the management of certain types of activities or functions, i.e. essentially distinguished responsibility centers, each of them has a specific purpose and responsibilities. Since the operation of each responsibility center corresponds to the most important areas of the organization, it can be recovered investment and innovation unit, which will provide the management of investment and innovation process. The functional organizational structure, which implies high level of competence of specialists for management of investment processes in large and medium-sized enterprises, but in the event of multiple divergent investment processes for the implementation of innovations of various kinds, such as technical and organizational, it cannot be fully effective. The problem can be partially solved by converting a functional organizational structure in a linear function with the delegation of the functional units of the rights to give orders to subordinate managers on variety of issues related to investment in innovation. Thefunctional organizational structure for small businesses is not suitable due to the already mentioned their limitations. In addition, investment and innovation activities of small businesses different risk and innovation, and the functional organizational structure are mainly oriented towards the solution of standard problems.

The matrix organizational structure is a combination of linear-functional organizational structures and design, resulting in a so-called matrix, which operates on the principle of double subordination. Addressing one of the variants of design structure matrix organizational structure implies submission to the members of the project team as a project manager and functional managers, project managers also are responsible for the integration of all activities and resources related to the project, the resources are transferred at the disposal of the project manager, project managers are fully responsible for the project functional managers delegate the project manager some of his duties and also monitor the progress of the tasks. The matrix organizational structures are increasingly being used in the Russian practice, they can quickly and flexibly take into account the potential and capabilities of personnel that fully meets the needs of Investment innovative processes in both large and medium and small enterprises. Typical here is the initial formation and precisely not the full investment and innovation department, and focus groups (software and target group) as an element of organizational structure of management of investment and innovation process, including all the actors with the distribution among them of the corresponding functions. As the economic practice of using focus groups as part of the matrix organizational structure allows us not only to achieve greater flexibility and coordination of work in view of the rapidly changing external environment, but also to get the desired results are not one but a number of investment and innovation projects.

Thereby matrix organizational structure is more suitable for management of investment and innovative processes in small businesses which is caused by the action of the macro - and microeconomic factors. The matrix organizational structure allows the use of the potential owners, managers and employees of small enterprises, which can act in one person, within not one but several investment and innovation projects, especially the investment and innovation process in the Russian small businesses require the simultaneous implementation of several innovations.

\section{SPECIFICS ORGANIZATIONAL ASPECTS OF THE MANAGEMENTOF INVESTMENT \& INNOVATIVE PROCESSES IN SMALL ENTREPRENEURSHIP}

The organizational structures of Russian small business which are existing nowadays- it's mostly traditional linear organizational structure of management, which is not provide the required level of quality control needs of investment processes, so they are subject to reform in the direction of creating centers of responsibility management of investment processes. The difficulty here is that the nature of small enterprises hinders the creation of complex organizational structures due to the small number of staff. Therefore, to overcome this contradiction is in the plane of adjusting the traditional organizational structures, by creating a way of life based on the business of small businesses it's kind of micro organizational structures, fully performing, however, the entire complex tasks of managing the investment and innovation processes. 
This may be a micro focus - groups to be produced in the initiation and development of investment and process, respectively to terminate after the completion of these processes. Micro focus groups could be the centers of the responsibility of management of investment processes in small enterprises and be responsible for items like investment and for the sources of their funding.

In our point of view, in the current conditions the most promising directions of the management of investment processes in small businesses we suggest improvement of all their constituents. It should be understood that the strategic and tactical components of the management of investment processes can be implemented by the same actors. Questions regarding the management strategy worked out and solved at the level of the owners, and tactical questions of implementation should be solved at the level of managers, as noted, in terms of small businesses they are often identical. In addition, microcenters of responsibility for investment management should develop and implement methodical maintenance of management in order to improve it for the investment activity of small businesses and increase its efficiency.

We considerthat to define the future characteristics of the necessary organizational structure to manage the investment and innovative processes in small business management are necessary to specify the nature of relations between its participants. In this sense, interesting is the approach according to which the configuration of the radiation released build relationships that lead to the centralization of powers and decisions of all linear functional tasks in a single body, the headquarters that positions centralizing staff functions in formations at different levels, and a matrix configuration of building ties that bind approaches and designs that are based on the orientation of the majority of duplex units [6]. Naturally, that the beam configuration generates linear-functional of organizational structure (line, staff, divisional and others).Matrix configuration - respectively complex pieces organizational structures (design, matrix, etc.). Consequently, the matrix organizational structure - it is not just the principle of dual subordination, but other content, compared linear functional organizational structures, two-way communication and orientation that adequately small business. The matrix organizational structure allows flexibility by improving bilateral relations smoothly implemented in the mode of the current financial and economic activity of the problem of formation and implementation of the strategy in the form of Investment innovative processes of a small business.

According to some experts the mobility and flexibility of the matrix organizational structure belong them to the number of adaptive structures. In a recent work revealed signs of adaptive organizational structures, which include: the lack of bureaucratic regulation of controls, flexibility, management structure, decentralization of decision-making, the creation of temporary controls, focus on the solution of complex projects and others. [9]. Actually, the matrix organizational structure of small businesses allows it to adapt to the changing conditions of the investment and innovation processes, moreover, the nature of investment and innovation activity of a small business requires, as noted, continued acceptance of all types of risk and innovation investment object, which means permanent changes in the external and internal environment, good governance which have the advantage of a matrix organizational structure.

A number of researchers classifying organizational structuresallocate part of their bureaucratic and organic types. The matrix organizational structure refers to an organic type, which is opposed to the type of bureaucratic and administrative activity characterized improvisation, flexibility, collegial and democratic decisionmaking, trust staff that ensures a constant and progressive willingness to negative changes in the environment [10]. It is natural that with such characteristics, matrix organizational structure of demand in small business, because of this small company structure responds to volatile external environment in a limited period of time can be up to not one but several purposes and uses a variety of diversified resources and can be reasonably managed investment \&innovative processes. Thus, the formation of matrix organizational structures instead of the classic in the subjects of small business in the interest of efficient management of investment and innovative processes should be carried out in the direction of selection and subordination elements linear function and design of organizational structures, establishment of a mechanism of dual subordination on the basis of bilateral ties and orientation to minimize risks and providing the best in- 
novative features of the investees.

Some scientists are considering the possibility of reforming the traditional organizational structures in small enterprises, the structure is isolated in the form of a circle, although it is sensitive to the difficulties and may be paralyzed due to the absence of any key employees, cruciform structure when decisions go through the head, located in the center of the cross although unstable in difficult situations in the absence of the head, and offer to implement star-shaped structure with a plurality of intersecting bonds, prepared for unexpected changes [11].

In our opinion, called modification of organizational structures, although formally consider and allow two-way communication between the participants in the management of small businesses, yet are not suitable in its pure form for the management of investment and innovative processes, because, first of all, regulate current economic activity. Investment and innovation as activities are strategic in nature and are looking for solutions of the strategic plan, which is known to take the owners of enterprises, including small businesses, acting in many cases, as already noted, managers and employees of small businesses. Therefore, it is necessary to form the organizational structure of management in small business adapted to the purposes of implementation of investment and innovation based on traditional structures evolving in matrix structures that carry the mechanism of bilateral ties.

\section{WAYS OF IMPROVEMENT ORGNIZATIONAL STRUCTURES OF SMALL BUSSINESS IN ORDER TO INCRESING MANAGEMENT OF INVESTMENT AND INNOVATION PROCESSES}

We suggest the following sequence of adjustment of the organizational structure of management of a small business, which includes four phases. In a small enterprise that has one of the classical organizational structures, such as linear, co-owners initiate the creation of an innovative organizational structure.

It is natural that in the framework of the basic linear organizational structure of small businesses, there are one-way links between the levels of government. This means that the investment decision, having for small business entities of strategic importance, you must hold a meeting of shareholders, which are often the top man- agers of small businesses. This is preceded by study of the parameters of the investment project in the departments and services of a small business, the formation of the business plan of the investment project, including industrial, technical, financial and marketing plans, in accordance with the principles of accounting and management. As a result, during the investment process is prolonged and dragged out, problems arise in the form of bureaucratic plan approvals, inconsistencies separate components, etc.This is contrary to the nature of small business and initially reduces the efficiency of investment projects.

Establishment of the principle of bilateral relations allows decisions to invest in innovation, by definition, have a long-term nature of the implementation, in the mode of the current financial and economic activity. In the presence of bilateral ties eliminates the need for additional regulations and bureaucratic procedures in the implementation of the investment process. Within the framework of the current financial and economic activity is a constant process of mining production, technical, financial, marketing, and accounting and management aspects of investment in innovation. However, a little bit away is the question of initiating investment and innovation processes, the answer to this question requires clarification - who specifically will make proposals for the initial parameters of investment in innovation? Therefore it is necessary to conduct a further modification of the base of the linear management structure by creating micro focus

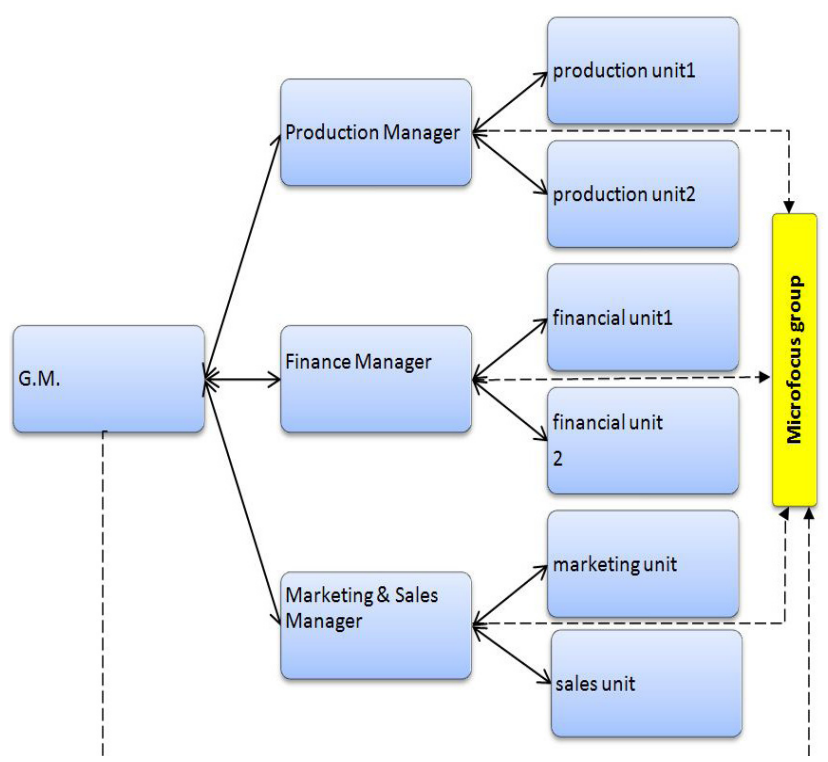

Figure 1: The introduction of micro focus groups in the basic linear organizational structure of small businesses 
The structure of the micro-focus group includes owner-managers of small businesses and the best experts on the basic linear units. Workingin the team of micro-focus group will take 10$15 \%$ of the total working time. The cost of a small business are minimized because the owners are motivated initially, and employees - due to the predominance of motivation through needs additional staff is not involved, substantial funding for organizational design available. The result the formation of a small business environment which include the productive suggestions, ideas, developments, inventions of all kinds of innovations generate investment and innovation.

\section{CONCLUSION}

The proposed investment management of innovative processes in small businesses organizational structure allows to decentralized way of managing. As we note before, the type of organic matrix organizational structure is characterized improvisation of management, flexibility, collegial and democratic decision-making, trust staff that ensures a constant willingness to change. Using a matrix organizational structure for the management of investment and innovative processes in small business allows you to work out reasonable proposals for investments in innovation and continue to concentrate all the resources in the hands of the head, but in the context of decentralization in the mode of bilateral ties.Decentralization allows you to initiate through the micro focus group is not one, but several innovative processes that correspond to the nature of the innovation activities of small businesses. This principle applies not only to the organizational structure of enterprises, but also in the industrial and technological and other structures. Later on projects cannot work alone, but several micro focus groups, created under the industrial, technological, financial, marketing and other directorates, decentralization will be present in each of these groups. On the other hand, in terms of small businesses, because of their known limitations, including the headcount, matrix organizational structure will exist in a shortened form, when the functions of the micro focus groups carried out a few professionals, but with basic units of small businesses operating under bilateral communications.

\section{ACKNOWLEDGEMENTS}

The article was published with the financial support from Ministry of Education and Science of the Russian Federation within the framework of state assignment to the project \#26.1511.2014K "Theory and methodology of managing innovational and investment processes in small business enterprises."

\section{REFERENCES:}

1) Balashov, A.P. (2008) Fundamentals of Management,M.:Textbook.

2) Barinov,v.A. (2010) Organization's design,M.: INFRA-M.

3) Brodel, F. (1988) Material civilization, economy and capitalism.Vol. 2.Exchange games,M.: Progress.

4) Doroshenko, Y.A.,Somina,I.V., \&Komissarov, S.A. (2013): Sources of Financing and Innovative and Investment Activity of Small Enterprises,World Applied Sciences Journal, 25(6), pp.975-982.

5) Doroshenko, Y.A.,Somina,I.V., Komissarov, S.A. \&Doroshenko, S.Y. (2015). The essence and characteristics of investment processes in small innovative enterprises, Asian Social Science,Vol. 11,N. 6.,pp. 185-191.

6) Grushenko, V.I. (2011) The perception of the essence of management in terms of strategic changes, M.:INFRA-M.

7) Miskon, M.H., Albert, M.,Hedoury, F. (1992)Fundamentals of Management,M.: Bussines.

8) New technology and organizational structures: Translate from English edited by I.Penni. подред. Й. Pennings, А. Byutandyam. - M.: Economy, 1990. - 268 p.

9) Pereverzev, M.P., Shaidenko, N.A., Basovsky, L.I. (2012) Management, M.:INFRA-M.

10)Raychenko, A.V. (2011) Administrative managementM.:INFRA-M.

11)Vissema, $H$. (1996) Management of the company's department (entrepreneurship \& coordination at the decentralized company), translated from English,M.:INFRA-M.

Paper sent to revision: 30.09.2015.

Paper ready for publication: 10.12.2015. 